\title{
Síntese de nanopartículas de prata revestida com PMAA para o controle de larvas do aedes aegypti
}

\author{
Gisele Silva de Santana ${ }^{1,2, *}$, Mariana T. Carvalho ${ }^{1}$, Audrey Nunes de Andrade ${ }^{1,2}$ \\ Maria Alice Varjal de Melo-Santos ${ }^{3}$, Anderson S. L. Gomes ${ }^{1}$ \\ ${ }^{1}$ Departamento de Física, UFPE, Recife, PE, Brasil, \\ ${ }^{2}$ Departamento de Química Fundamental, UFPE, Recife, PE, Brasil, \\ ${ }^{3}$ Instituto Aggeu Magalhães, Recife, PE, Brasil. \\ *gisele_s@hotmail.com
}

\section{INTRODUÇÃO}

Diversos agentes antimicrobianos foram desenvolvidos para curar e impedir doenças na higiene da saúde pública e na indústria biomé dica [1]. Entre eles, as nanopartículas de prata (AgNP) foram aprovadas como promissores agentes antimicrobianos em virtude do seu potencial biocida efetivo e a não toxicidade para o ser humano [2].

As sínteses de nanopartículas de prata são bem compreendidas e inúmeras técnicas foram desenvolvidas levando a um controle sobre a forma e o tamanho dessas partículas [3]. Na maioria das sí nteses de nanopartículas de prata é primordial a utilização de um reagente adicional de passivação superficial, incluindo moléculas de surfactantes e polímeros, para impossibilitar que as nanopartí culas se agreguem dentro da suspensão líquida [4]. 0 uso de polieletrólitos para a redução da prata demonstra um benefício de atuar tanto como agente redutor quanto como agente estabilizador [3].

Dentre uma gama extensa de polieletrólitos encontrados na literatura científica, a utilização do Ácido Polimetacrílico (PMAA), propicia infinitos benefícios por causa das suas propriedades físicas e químicas, tais como a solubilidade na água e a capacidade de coordenação das nanopartículas metálicas [4].

A biocompatibilidade e a inocuidade do polímero PMAA tornam o á cido adequado para aplicação biomédica. Com todas essas características supracitadas, o emprego de nanopartículas de prata revestidas com PMAA vem a se tornar um promissor material para o controle vetorial do mosquito Aedes aegypti [5]. O Aedes aegypti é um dos mais importantes vetores de arbovírus para o homem, pois está envolvido na transmissão dos vírus Dengue, Chikungunya e Zika. Esta espécie atingiu o continente Americano após desenvolver grau significante de sinantropia [6]. O Aedes aegypti está bem habituado aos ambientes urbanos, principalmente em localidades com problemas de abastecimento de água, infraestrutura e saneamento básico, como o Nordeste do país.

0 uso de inseticidas químicos convencionais para o controle de larvas e mosquitos adultos promove a seleção de populações mais resistentes a alguns destes compostos [7]. Desta forma, a procura por novas substâncias com ações inseticidas e larvicidas são necessárias para garantir que esta estratégia de controle do mosquito continue sendo uma opção [5].

\section{MATERIAIS E MÉTODOS}

As nanopartículas de prata são induzidas por irradiação UV. A sí ntese (figura 1) consiste em adicionar $25 \mathrm{~mL}$ de solução de $\mathrm{AgNO}_{3}$ $0,5 \mathrm{mM}$ a uma solução de $25 \mathrm{~mL}$ de PMAA $5 \mathrm{mM}$. Essa mistura é colocada sob agitação durante 5 minutos e posteriormente é posta sob irradiação UV durante 6 horas.

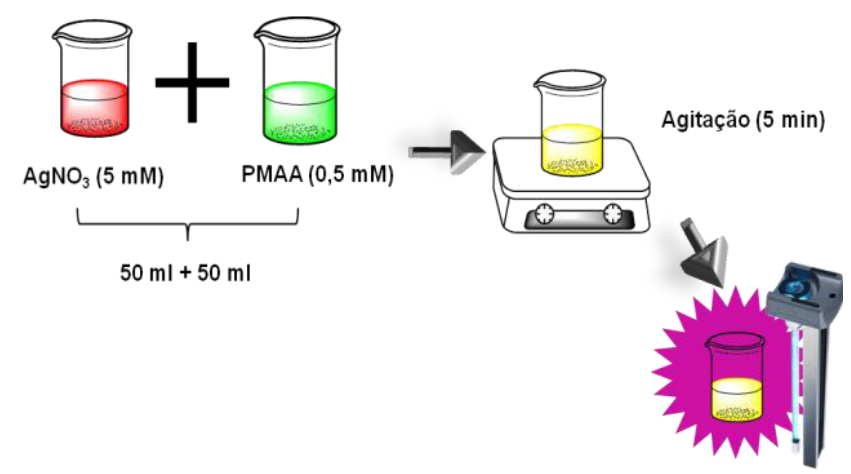

Figura 1: Síntese de nanopartícula de prata por irradiação UV durante 6 horas.

As nanopartículas foram caracterizadas para determinar o comprimento de onda através da espectroscopia na região utravioleta e visível (UV-vis), imagens de microscopia eletrônica de transmissão (MET), imagens de microscopia óptica e tomografia de coerência óptica (OCT).

Após as caracterizações foram realizados os bioensaios no departamento de Entomologia/CPqAM-Fiocruz, Universidade Federal de Pernambuco.

\section{RESULTADOS E DISCUSSÃO}

As nanopartículas metálicas têm uma alta energia superficial, beneficiando termodinamicamente a agregação destas para a formação metal-metal. Esta agregação pode ser evitada com a inserção de estabilizadores formando uma camada auto-organizada que impedem a aderência. Desta forma é utilizado o polímero PMAA que possui uma grande afinidade pelas nanopartículas e uma cadeia orgânica longa que gera impedimento estérico suficiente para evitar interações entre as mesmas. 
As amostras sintetizadas apresentaram uma coloração amarelada quando expostas a irradiação UV, por um tempo de reação de $6 \mathrm{~h}$, o que está associado com a excitação eletrônica. $\mathrm{O}$ pH da síntese deve permanecer constante em 8.4, pois a alteração deste para o meio ácido pode comprometer a eficiência do polímero para alcanc ar a redução da prata, bem como a estabilidade das partículas. 0 espectro de UV-vis (figura 2) apresentou um pico intenso em aproximadamente $430 \mathrm{~nm}$, referente à ressonância dos plasmons da superfície dessas nanopartículas.

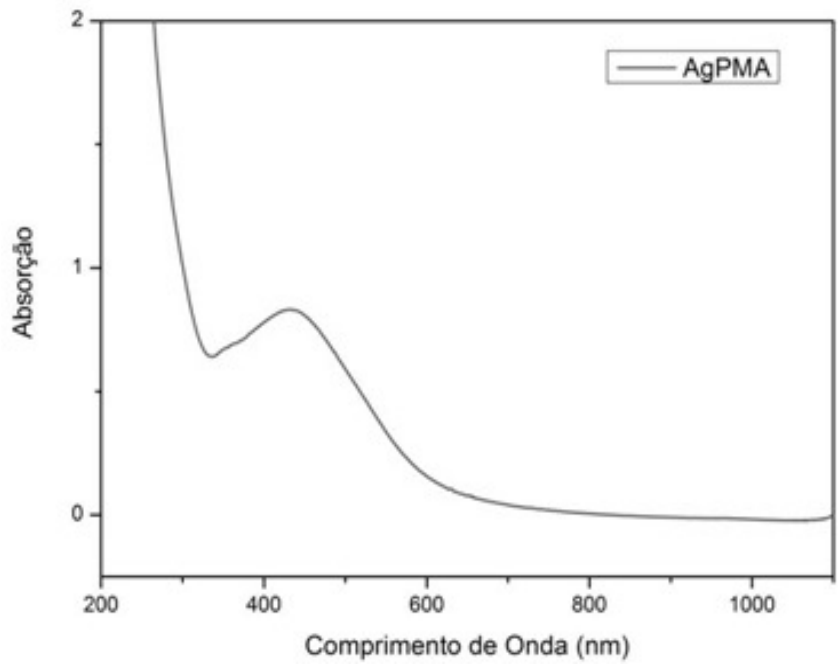

Figura 2: Espectro de absorção da sínteses de nanopartícula de prata revestida com PMAA.

O diâmetro das nanopartículas foi determinado através da microscopia eletrônica de transmissão (figura 3), no qual obtivemos um tamanho de aproximadamente $9 \mathrm{~nm}$. Desta forma, a estabilidade do sistema foi decorrente do fato de que as nanopartí culas formadas permaneceram em suspensão e não se agregaram para a formação de partículas maiores.

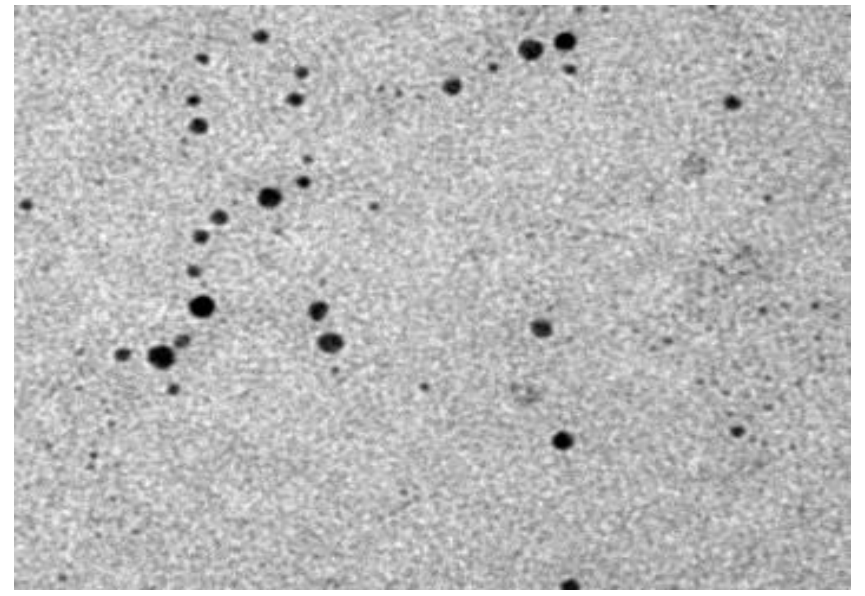

Figura 3: Imagem TEM para nanopartículas de prata com capa de PMAA.

Durante o bioensaio foi observado que a mortalidade das larvas depende do tempo de exposição das mesmas com as nanopartí culas, bem como suas concentrações (tabela 3). Vinte larvas de Aedes aegypti em $4^{\circ}$ estádio de desenvolvimento foram depositadas em recipientes contendo $100 \mathrm{ml}$ de água e diferentes volumes do nanolarvicida (figura 6). Após 24 horas, a quantidade de larvas é avaliada para analisar a eficiência da amostra.
Tabela 3: Mortalidade larval registrada em 24h. Cada amostra foi testada com 20 larvas de $4^{\circ}$ estádio de desenvolvimento

\begin{tabular}{|c|c|c|}
\hline $\begin{array}{c}\text { Volume solução } \\
\text { Nanopartícula }(\boldsymbol{\mu l})\end{array}$ & $\begin{array}{c}\text { Concentração } \\
(\mathbf{m g} / \mathbf{L})\end{array}$ & $\begin{array}{c}\text { AgPMA } \\
\mathbf{( \% )}\end{array}$ \\
\hline 10 & 0,004 & 12,5 \\
\hline 20 & 0,009 & 25 \\
\hline 30 & 0,013 & 82,5 \\
\hline 50 & 0,022 & 92 \\
\hline 70 & 0,031 & 100 \\
\hline 100 & 0,045 & 100 \\
\hline
\end{tabular}

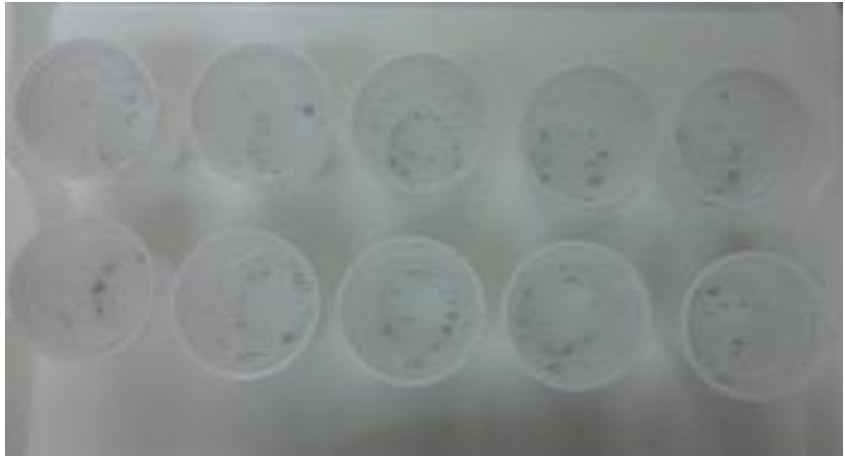

Figura 4: Bioensaios das larvas de Aedes aegypti em $4^{\circ}$ estádio de desenvolvimento.

De acordo com os dados apresentados, nota-se que a amostra desta forma, para nanopartículas com diâmetro aproximadamente 10 $\mathrm{nm}$, há uma especulação que a causa da morte das larvas é devido à penetração da prata na membrana larval.

$\mathrm{Na}$ sequência dos bioensaios, houve a coleta de algumas larvas controle (sem nanopartícula) e larvas com nanopartícula para a aná lise de microscopia óptica (figura 5 a,b).

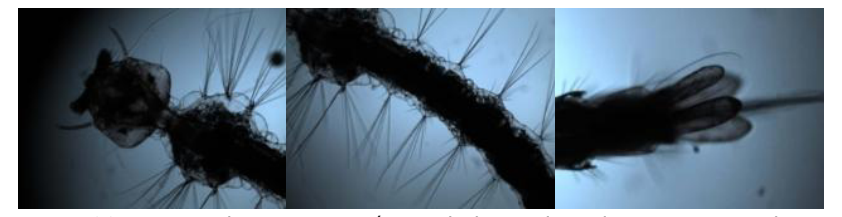

Figura 5 (a): Imagens de microscopia óprica de larvas de aedes aegyoti controle (sem nanopartícula de prata).

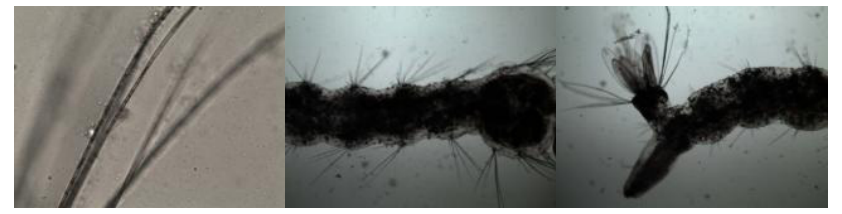

Figura 5 (b): Imagens de microscopia óprica de larvas de aedes aegyoti com nanoparti cula de prata.

Também foi analisado uma possível elucidação da morfologia da Aedes controle e morta pela presença de nanopartículas através da tomografia de coerência óptica (OCT). O OCT permite a observação de diferentes camadas da larva, com uma boa penetração da luz em seu tecido (Figura 6).

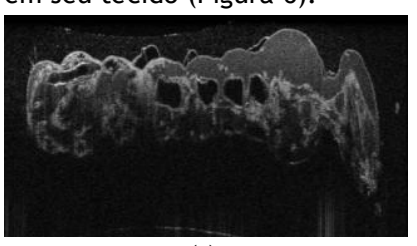

(a)

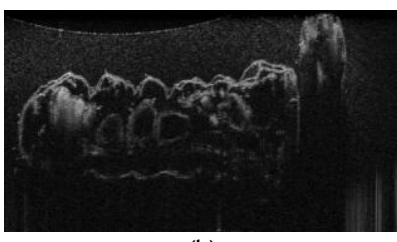

(b)
Figura 6: Imagens de OCT (a) da larva controle e de uma (b) larva com morte pelo AgPMAA.

\section{CONCLUSÕES}

Os resultados obtidos neste estudo confirmam a atividade larvicida das nanopartículas de prata para o Aedes aegypti, que, juntamente com a facilidade e o baixo custo de sua produção, revelam o 
grande potencial para o desenvolvimento tecnológico deste nanocompósito para controle de larvas.

\section{REFERÊNCIAS}

Silver, S. "FEMS Microbio". ReV.27, (2003), 341 - 353

Kong, H., and Jang, J., "Antibacterial properties of novel Poly(methyl methacrylate) nanofiber containing silver nanoparticles", Langmuir, 24,(2008)2051 - 2056

Dubas, T. S., Kumlangdudsana, P., Potiyaraj, P., "Layer-by-layer deposition of antimicrobial silver nanoparticles on textile fibers", Colloids and Surfaces A: Physicochem. Eng. Aspects 289 (2006) 105109

Spadaro, D., Barletta, E., Barreca, F., Curro, G., "PMA capped silver nanoparticles produced by UV-enhanced chemical process", Applied Surface Science 255 (2009) 8403-8408.

Sap-lam, N., Homklinchan, C., Larpudomlert, R., Warisnoicharoen., Sereemaspun, A. and Dubas, T. S., "UV irradiation-induced silver nanoparticles as mosquito larvicides", Journal of applied sciences 10 (23): (2010) 3132 - 3136;

Gomes, C. A., "Medidas dos níveis de infestação urbana para aeses aegypti e aedes albopictus em programa de vigilância entomoló gica!", Departamento de Epidemiologia da Faculdade de Saúde Pú blica da Universidade de São Paulo.

Torres, S. M., Cruz, N. L. N., Rolim, V. P. M., Cavalcanti, M. I. A., Alves, L. C., Júnior, V. A. M., "Cumulative mortality of Aedes aegypti larvae treated with compounds”, (2014) 